University of Nebraska - Lincoln

DigitalCommons@University of Nebraska - Lincoln

\title{
Effect of Malondialdehyde-Acetaldehyde-Protein Adducts on the Protein Kinase C-Dependent Secretion of Urokinase-Type Plasminogen Activator in Hepatic Stellate Cells
}

\author{
Kusum K. Kharbanda \\ University of Nebraska Medical Center, kkharbanda@unmc.edu \\ Kris A. Shubert \\ Department of Veteranr Affazrs Medzcal Centel; VA Alcohol Research Centel; 4101 Woolworth Avenue, \\ Omaha, NE \\ Todd A. Wyatt \\ Department of Veteranr Affazrs Medzcal Centel; VA Alcohol Research Centel; 4101 Woolworth Avenue, \\ Omaha, NE \\ Michael F. Sorrell \\ Department of Veteranr Affazrs Medzcal Centel; VA Alcohol Research Centel; 4101 Woolworth Avenue, \\ Omaha, NE \\ Dean J. Tuma \\ Department of Veteranr Affazrs Medzcal Centel; VA Alcohol Research Centel; 4101 Woolworth Avenue, \\ Omaha, NE \\ Follow this and additional works at: https://digitalcommons.unl.edu/publichealthresources \\ Part of the Public Health Commons
}

Kharbanda, Kusum K.; Shubert, Kris A.; Wyatt, Todd A.; Sorrell, Michael F.; and Tuma, Dean J., "Effect of Malondialdehyde-Acetaldehyde-Protein Adducts on the Protein Kinase C-Dependent Secretion of Urokinase-Type Plasminogen Activator in Hepatic Stellate Cells" (2002). Public Health Resources. 68. https://digitalcommons.unl.edu/publichealthresources/68 


\title{
Effect of malondialdehyde-acetaldehyde-protein adducts on the protein kinase C-dependent secretion of urokinase-type plasminogen activator in hepatic stellate cells
}

\author{
Kusum K. Kharbanda ${ }^{\mathrm{a}, \mathrm{b}, *}$, Kris A. Shubert ${ }^{\mathrm{a}}$, Todd A. Wyatt ${ }^{\mathrm{a}, \mathrm{b}}$, \\ Michael F. Sorrell ${ }^{\mathrm{a}, \mathrm{b}}$, Dean J. Tuma ${ }^{\mathrm{a}, \mathrm{b}}$ \\ ${ }^{a}$ Department of Veterans Affairs Medical Center, VA Alcohol Research Center, 4101 Woolworth Avenue, Omaha, NE 68105, USA \\ ${ }^{\mathrm{b}}$ Department of Internal Medicine, University of Nebraska Medical Center, Omaha, NE 68198, USA
}

Received 20 April 2001; accepted 20 June 2001

\begin{abstract}
Previous studies from our laboratory have shown that malondialdehyde-acetaldehyde-protein adducts (MAA adducts) are formed in hepatocytes of ethanol-fed rats and directly influence the hepatic stellate cells (HSCs) to induce their secretion of chemokines and to upregulate their expression of adhesion molecules. Since protein kinase C $(\mathrm{PKC})$ is known to play a major role in many diverse intracellular signal transduction processes, we investigated whether MAA adducts influence the function of HSCs via a PKC-dependent pathway. HSCs in culture were exposed to MAA adducts, and PKC activity was determined. We observed a time- and concentration-dependent activation of PKC when cultures were exposed to BSA-MAA as compared with unmodified BSA. Using PKC isoform-specific inhibitors, we also showed that BSA-MAA induces the activation of a specific isoform of PKC, PKC- $\alpha$, in HSCs. No activation of PKC was observed when HSCs were exposed to other aldehyde adducts such as BSA-acetaldehyde or BSA-malondialdehyde, indicating that the effects of MAA adducts on HSCs were somewhat specific. We further examined whether the observed increase in PKC activation induced by MAA adducts in HSCs, in turn, causes a functional effect. We observed that BSA-MAA induces the increased secretion of urokinase-type plasminogen activator, a key component of the plasmin-generating system, and that PKC activation is necessary for this enhanced urokinase-type plasminogen activator secretion. These results indicate that MAA adducts via a PKC-mediated pathway may regulate plasmin-mediated matrix degradation in the liver, thereby contributing to the progression of hepatic fibrosis.
\end{abstract}

Keywords: MAA adducts; Urokinase-type plasminogen activator; PKC; Alcoholic liver disease; Hepatic stellate cells

\section{Introduction}

Key players in the pathogenesis of alcohol-induced liver injury are the HSCs [1-3]. HSCs normally reside in the space of Disse in a quiescent, non-proliferative state, in close contact with all the major resident liver cells. Following hepatic injury, regardless of etiology, HSCs undergo a

\footnotetext{
* Corresponding author. Tel.: +1-402-346-8800x3736; fax: +1-402-449-0604.

E-mail address: kkharbanda@unmc.edu (K.K. Kharbanda).

Abbreviations: HSCs, hepatic stellate cells; ECM, extracellular matrix; MAA adducts, malondialdehyde-acetaldehyde-protein adducts; MDA, malondialdehyde; PKC, protein kinase C; PA, plasminogen activator; uPA,

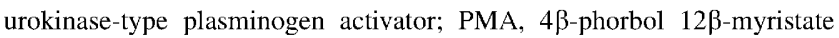
13-acetate; MCP-1, macrophage chemotactic protein-1; MIP-2, macrophage inflammatory protein-2; ECL, enhanced chemiluminescence.
}

complex activation process and become the principal source for the increased and irregular deposition of extracellular matrix (ECM) components, which characterizes fibrosis and cirrhosis [4-7]. In addition, HSCs participate in matrix remodeling through the synthesis of matrix metalloproteinases, tissue inhibitors of metalloproteinases, cytokines, and components of the plasminogen-activating systems [8-14].

Many of the toxic effects of ethanol have been linked to the formation of adducts, resulting from the covalent binding of highly reactive aldehydes such as acetaldehyde, malondialdehyde (MDA), and 4-hydroxynonenal, produced in the liver during ethanol ingestion, to hepatic proteins, as playing a significant role in the development of liver injury [15-18]. Recent studies from our laboratory have shown that acetaldehyde, derived from ethanol metabolism, and the lipid peroxidation-derived aldehyde, MDA, can react 
together with proteins in a synergistic manner to form new and distinct hybrid adducts, designated as MAA adducts [19]. Definitive chemical characterization of MAA adducts has revealed two major structural forms. In addition to the highly fluorogenic and immunogenic 2:1 MAA adduct, in which 2 moles of MDA and 1 mole of acetaldehyde combine with an amino group of proteins, a 1:1 adduct in which 1 mole each of MDA and acetaldehyde combine with an amino group of a protein has been shown to be the other major adduct [20]. Studies from our laboratory have shown that MAA adducts are formed in hepatocytes of ethanolfed rats [21] and induce the secretion of two chemokines, macrophage chemotactic protein-1 (MCP-1) and macrophage inflammatory protein-2 (MIP-2), as well as increase the expression of intercellular adhesion molecule-1 in HSCs in vitro [22]. These results indicated that the MAA adducts could directly affect HSCs and contribute to the pathogenesis of alcoholic liver injury.

$\mathrm{PKC}$ is known to play a major role in intracellular signal transduction affecting such processes as proliferation, differentiation, migration, inflammation, and cytoskeletal organization. Investigations over the past decade have shown that many effects of ethanol on cell functions are closely interconnected with PKC [23]. Since other laboratories have reported the activation of PKC in HSCs consequent to exposure to aldehydes [24,25], in this study we investigated whether the effects of MAA adducts on HSCs are transduced via a PKC-dependent pathway. In macrophages, a classical PKC activator, $4 \beta$-phorbol $12 \beta$-myristate 13-acetate (PMA), has been shown to up-regulate a key component of the plasminogen activating system, urokinase-type plasminogen activator (uPA) [26]. Because both human and rat HSCs have been shown to produce uPA $[13,14]$, we also investigated the effect of MAA adducts on the secretion of uPA by these cells. We observed that BSAMAA induces the activation of PKC and increases the secretion of $\mathrm{UPA}$ and that PKC activation is necessary for BSA-MAA-induced enhancement of uPA secretion.

\section{Materials and methods}

\subsection{Materials}

BSA (Fraction V, fatty acid-free, low endotoxin), collagenase, Stractan, casein, PMA, and monoclonal antismooth muscle $\alpha$-actin were obtained from the Sigma Chemical Co. Acetaldehyde was obtained from the Aldrich Chemical Co. A chromogenic LAL assay kit was obtained from BioWhittaker. Pronase and DNAse were from the Boehringer Mannheim Corp. Dulbecco's modified Eagle's/ F-12 medium (DMEM/F12), glutamine, solutions of antibiotics and an antifungal agent, and trypsin-EDTA were from Gibco-BRL. Fetal bovine and horse serum were from HyClone Laboratories. The avidin-biotin peroxidase kit was from Vector Laboratories. The PKC inhibitors
Gö 6976, rottlerin, myristylated-PKC- $\zeta$, and calphostin $C$ were obtained from the Calbiochem-Novobiochem Corp. A Biotrack PKC enzyme assay kit, $\left[\gamma-{ }^{32} \mathrm{P}\right] \mathrm{ATP}$, and an enhanced chemiluminescence (ECL) immunodetection kit were obtained from Amersham Pharmacia. Plasminogen and D-Val-Leu-Lys-aminomethyl coumarin (plasmin substrate) were obtained from Enzyme Systems Products. Purified uPA and antibody to uPA were obtained from American Diagnostica Inc. Peroxidase-conjugated anti-rabbit secondary antibody was from Jackson Immunoresearch Laboratories. Nitrocellulose membrane was obtained from Bio-Rad. Protein concentration was measured using the BCA protein assay reagent obtained from Pierce. All other chemicals used in this study were obtained from the Fischer Scientific Co.

\subsection{Generation of BSA-MAA and other adducts}

BSA-MAA was generated by incubating $1 \mathrm{mg} / \mathrm{mL}$ of BSA with an equimolar $(1 \mathrm{mmol} / \mathrm{L})$ solution of MDA and acetaldehyde for 3 days at $37^{\circ}$ in a sealed polypropylene vessel in a non-oxidizing atmosphere as detailed in our earlier publication [19]. Unmodified BSA was used as a control. Additional controls such as acetaldehyde- or MDAadducts of these proteins were made utilizing similar conditions for incubation and with the same molar concentration of acetaldehyde or MDA alone as used in the generation of MAA adducts. Since HSCs are responsive to LPS and results in activation of $\mathrm{PKC}$, ${ }^{1}$ we took utmost care to generate the various adducts under pyrogen-free conditions. The endotoxin levels in our adducted and nonadducted samples, monitored using the chromogenic LAL assay, were always below the detectable range of $<0.06$ endotoxin units/mL.

\subsection{Isolation and culture of HSCs}

Male Wistar rats (Charles River Laboratories) were maintained at the Omaha VA Medical Center animal facility accredited by the American Association for the Accreditation of Laboratory Animal Care (AAALAC). All animals received humane care in accordance with the guidelines of the National Institute on Drug Abuse, National Institute of Health, and the Guide for the Care and Use of Laboratory Animals (Institute of Laboratory Animal Resources, Commission on Life Sciences, National Research Council, 1996).

The HSCs were isolated from 3-month-old rats using sequential pronase and collagenase perfusion followed by density gradient centrifugation with Stractan [27]. The viability of the cells was evaluated by trypan blue exclusion, and HSCs were identified by their typical phase contrast light microscopic appearance and by the presence of fat droplets detected by ultraviolet light. The purified

${ }^{1}$ Kharbanda KK and Tuma DJ, unpublished observations. 
HSCs were cultured on uncoated plastic (75- $\mathrm{cm}^{2}$ flask) at $37^{\circ}$ in a humidified atmosphere containing $5 \% \mathrm{CO}_{2}$ as described by Friedman and Roll [27] in 1:1 DMEM/F12 supplemented with $10 \%$ fetal bovine serum, $10 \%$ horse serum, $2 \mathrm{mmol} / \mathrm{L}$ of glutamine and $1 \%$ solutions of antibiotics and an antifungal agent. The medium was replaced $24 \mathrm{hr}$ after seeding the cells and every $48 \mathrm{hr}$ thereafter. At confluence, the cells were detached with a trypsin-EDTA solution and split 1:4 each time for subculture. A representative from each subculture was stained by the avidinbiotin peroxidase technique following the instructions of the manufacturer (Vector Laboratories) using monoclonal anti-smooth muscle $\alpha$-actin. Under these culture conditions, HSCs proliferated and became fully activated within 8-10 days of primary culture.

The experiments described in this study were done on 59 independent cell lines and were performed between passages 1 and 6 . The HSCs in passages 1-6, all of which were smooth muscle $\alpha$-actin positive (indicating that all these cells were activated), were trypsinized, and $2.5 \times 10^{5}$ cells were plated in uncoated $60-\mathrm{mm}$ petri dishes in serum containing medium for PKC-related studies. When the plates were $60 \%$ confluent, the cells were washed with medium without serum and exposed to unmodified BSA or BSA-MAA in serum-free medium for up to $72 \mathrm{hr}$. At the end of the exposure time, tissue culture medium was discarded, $250 \mu \mathrm{L}$ of cold lysis buffer $(50 \mathrm{mmol} / \mathrm{L}$ Tris$\mathrm{HCl}, \mathrm{pH} \mathrm{7.4,} \mathrm{containing} \mathrm{leupeptin,} \mathrm{phenylmethylsulfonyl}$ fluoride, and aprotinin) was added immediately, and the dishes were flash-frozen for PKC assay. To establish the specificity of BSA-MAA, HSCs were also exposed to BSA-acetaldehyde or BSA-MDA adducts, and the activity of PKC was determined.

\subsection{Assay of PKC activity}

The cells were scraped from dishes and sonicated. The cell lysate was centrifuged at $10,000 \mathrm{~g}$ for $30 \mathrm{~min}$ at $4^{\circ}$ to separate the cytosolic and particulate fractions. The particulate fraction was extracted with lysis buffer containing Triton X-100. PKC activity was determined in both fractions by a procedure employed previously [28] using the substrate peptide (VRKRTLRRL) in $20 \mu \mathrm{L}$ of kit mix and $20 \mu \mathrm{L}$ of $\mathrm{Mg}-\left[\gamma_{-}{ }^{32} \mathrm{P}\right]$ ATP in a Tris- $\mathrm{HCl}$ buffer $(\mathrm{pH} 7.5)$. Samples $(20 \mu \mathrm{L})$ were added to $40 \mu \mathrm{L}$ of the above reaction mixture and incubated for $15 \mathrm{~min}$ at $30^{\circ}$. Incubations were stopped by spotting $50 \mu \mathrm{L}$ of each sample onto P-81 phosphocellulose paper (Whatman). The papers were washed five times for $5 \mathrm{~min}$ each in $75 \mathrm{mmol} / \mathrm{L}$ of phosphoric acid and one time in ethanol and then air-dried and counted in non-aqueous scintillant. Kinase activity was calculated in relation to total cellular protein assayed and was expressed in $\mathrm{pmol} /(\mathrm{min} \mathrm{mg})$. No less than three independent tests on different cellular preparations were performed per parameter. Data were analyzed for statistical significance using Student's $t$-test.

\subsection{Effect of BSA-MAA on UPA secretion by HSCS}

The secretion of uPA was quantitated by chromogenic substrate assay, casein zymography, and Western blotting techniques. For these studies, cells grown in uncoated 24-well plates in serum-containing medium were washed twice with serum-free medium and incubated with BSAMAA or unmodified BSA in $1 \mathrm{~mL}$ of serum-free DMEM/ F12 for $24 \mathrm{hr}$. After incubation, the media were collected, centrifuged at $10,000 \mathrm{~g}$ for $7 \mathrm{~min}$ at $4^{\circ}$, and the supernatants were stored at $-70^{\circ}$ until assay. The cells were lysed in $250 \mu \mathrm{L}$ of $0.1 \%$ SDS to determine total DNA [29].

\subsection{Determination of uPA activity by chromogenic substrate assay}

Quantification of uPA activity in the conditioned medium was performed utilizing a functional assay for plasmin [26]. Briefly, purified uPA or aliquots $(300 \mu \mathrm{L})$ of serumfree supernatants of conditioned medium were added to tubes with buffer (PBS, pH 7.6, with 0.05\% Tween-20). Then $5 \mu \mathrm{g}$ of plasminogen and $13 \mu \mathrm{g}$ of the plasmin substrate D-Val-Leu-Lys-aminomethyl coumarin were added to all tubes. Each conditioned medium sample had its own blank in which no plasminogen was added. This was done to eliminate interference in the assay by plasmin or other non-specific proteases in the sample. Samples were mixed and incubated in a $37^{\circ}$ water bath. The concentration of aminomethyl coumarin produced was measured fluorometrically at excitation and emission wavelengths of 370 and $460 \mathrm{~nm}$, respectively. Activity of plasminogen activator (PA) in the conditioned medium was extrapolated from a standard curve utilizing purified uPA, and the data were expressed as mIU/ $\mu \mathrm{g}$ of DNA.

\subsection{Casein zymography}

For the detection of PA by zymography, samples of conditioned media were separated on $10 \%$ SDS-polyacrylamide gels containing $2 \mathrm{mg} / \mathrm{mL}$ of casein and $0.25 \mathrm{mg} / \mathrm{mL}$ of plasminogen under non-reducing conditions according to the zymography procedure of Waghray and Webber [30]. The volume of the conditioned medium loaded per lane was such that it corresponded to an equal cell number or DNA amount. After electrophoresis, the gels were incubated for $30 \mathrm{~min}$ in a $2.5 \%$ solution of Triton X-100 and then incubated overnight at $37^{\circ}$ in $50 \mathrm{mmol} / \mathrm{L}$ of Tris, $100 \mathrm{mmol} / \mathrm{L}$ of $\mathrm{NaCl}, \mathrm{pH}$ 7.6. The gels were stained with a $0.5 \%$ solution of Coomassie blue and destained in $30 \%$ methanol and 10\% acetic acid. The uPA activity (caseinolytic activity) was identified as clear bands on a uniform blue background following destaining. The gels were dried, and densitometric analyses were performed using the Molecular Dynamics personal SI and ImageQuant software. To rule out the possibility that the activity being determined by casein zymography was not due to plasmin, 
conditioned media were also separated in casein-SDSpolyacrylamide gels in the absence of plasminogen.

\subsection{Western blotting}

Samples of conditioned media (corresponding to an equal cell number or DNA amount) in electrophoresis loading buffer $[50 \mathrm{mmol} / \mathrm{L}$ of Tris- $\mathrm{HCl}(\mathrm{pH} 6.8), 2 \%$ SDS, $2 \% \beta$-mercaptoethanol, $10 \%$ glycerol, and $0.001 \%$ bromophenol blue] were separated on a $10 \%$ SDS-polyacrylamide gel. Protein transfer was performed onto a nitrocellulose filter using a transblot apparatus containing $25 \mathrm{mmol} / \mathrm{L}$ of Tris- $\mathrm{HCl}(\mathrm{pH} 8.3), 192 \mathrm{mmol} / \mathrm{L}$ of glycine, and $20 \%$ methanol. The blots were blocked for $1 \mathrm{hr}$ at $37^{\circ}$ with Blotto (PBS, pH 7.4, 0.05\% Tween-20, 5\% nonfat dry milk) and then were incubated overnight in Blotto containing 1:1000 diluted polyclonal antibody against uPA. After extensive washing in PBS-Tween-20, the blots were incubated for $1 \mathrm{hr}$ at $25^{\circ}$ in Blotto containing $0.5 \mu \mathrm{g} / \mathrm{mL}$ of peroxidase-conjugated anti-rabbit secondary antibody. Blots were washed extensively with PBS-Tween-20, washed once with PBS, developed using ECL, and exposed to film. Densitometric analyses were performed using the Molecular Dynamics personal SI and ImageQuant software.

\subsection{Statistical analysis}

Statistical analysis was performed by the paired Student's $t$-test. A probability value of $<0.05$ was considered significant.

\section{Results}

To examine whether BSA-MAA activates PKC in HSCs, we initially exposed HSCs to $50 \mu \mathrm{g} / \mathrm{mL}$ of BSAMAA or unmodified BSA for up to $72 \mathrm{hr}$. We observed a time-dependent activation of PKC activity in HSCs treated with $50 \mu \mathrm{g} / \mathrm{mL}$ of BSA-MAA (Fig. 1). BSA-MAA maximally activated PKC (2.0-fold increase, $P<0.05)$ at $2 \mathrm{hr}$ after exposure compared to the medium control and decreased to unstimulated levels by $24 \mathrm{hr}$ and remained so at 48 and $72 \mathrm{hr}$ (Fig. 1). In contrast to BSA-MAA, there was no effect of unmodified BSA on PKC activation at any of the time points tested. To determine the concentrationdependent effect of BSA-MAA on HSCs, the cells were treated with $0-100 \mu \mathrm{g} / \mathrm{mL}$ of BSA-MAA for $2 \mathrm{hr}$. We observed a concentration-dependent activation of PKC up to $62.5 \mu \mathrm{g} / \mathrm{mL}$, beyond which a decrease in PKC activity was observed (Fig. 2). To establish the specificity of the BSA-MAA response, we also examined other aldehyde adducts. At a concentration similar to that of BSA-MAA, which induced activation of PKC, no effect of $50 \mu \mathrm{g} / \mathrm{mL}$ of BSA-acetaldehyde or BSA-MDA adduct was observed at either 2 or $24 \mathrm{hr}$ of treatment (Table 1).

Rat HSCs have been shown to express at least four different PKC isoforms: PKC $-\alpha,-\delta,-\varepsilon$, and $-\zeta$ [31]. To further delineate which isoform of PKC is activated by BSA-MAA, we used isoform-specific inhibitors $1 \mathrm{hr}$ before exposing the cells for $2 \mathrm{hr}$ to $50 \mu \mathrm{g} / \mathrm{mL}$ of BSAMAA. The various inhibitors used were $100 \mathrm{nmol} / \mathrm{L}$ of Gö 6976 (PKC- $\alpha$ specific inhibitor), $2 \mu \mathrm{mol} / \mathrm{L}$ of rottlerin (PKC- $\delta$ specific inhibitor), $40 \mathrm{nmol} / \mathrm{L}$ of myristylated-

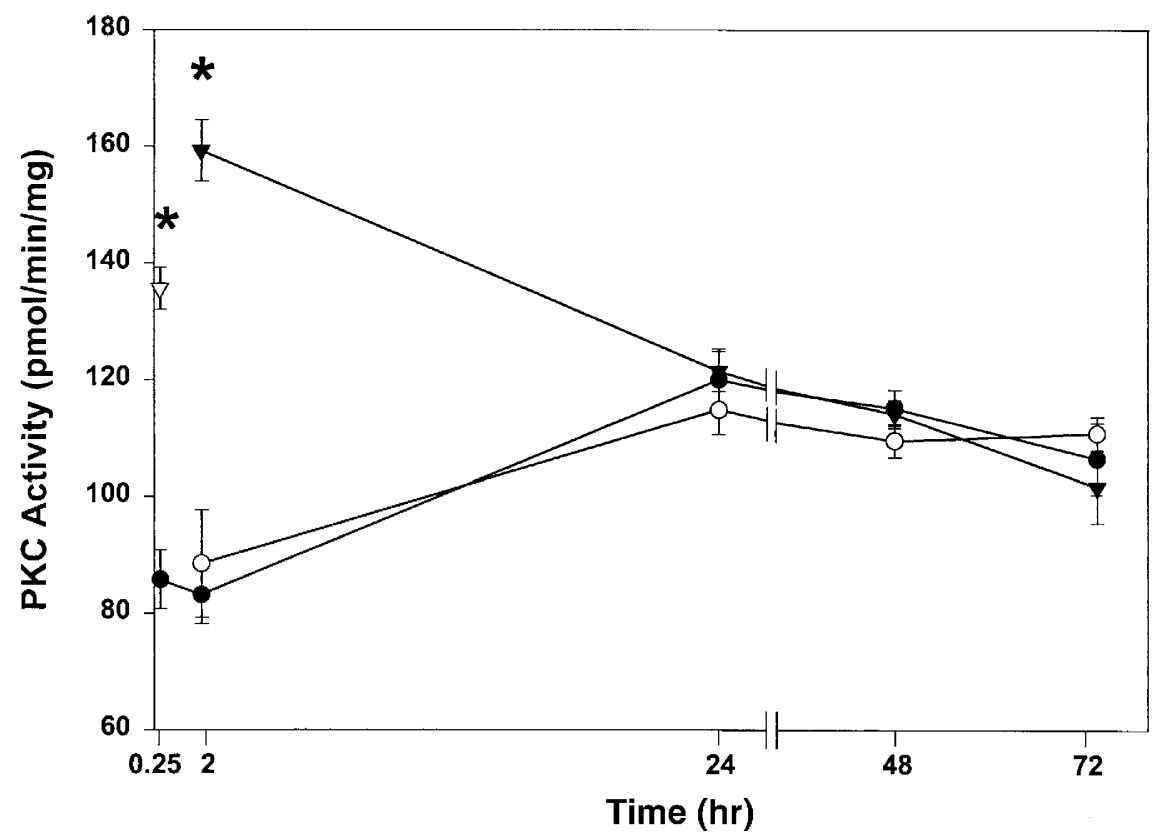

Fig. 1. Time course of BSA-MAA-induced PKC activation. PKC activity was determined in HSCs exposed to medium alone (O $50 \mu \mathrm{g} / \mathrm{mL}$ of unmodified BSA (O), or $50 \mu \mathrm{g} / \mathrm{mL}$ of BSA-MAA $(\nabla)$ for up to $72 \mathrm{hr}$. PMA $(\nabla)$ at a concentration of $100 \mathrm{ng} / \mathrm{mL}$ was used as a positive control. Results are presented as means \pm SEM of four determinations. An asterisk $(*)$ indicates that the value is significantly different $(P<0.05)$ from the medium-alone control. 


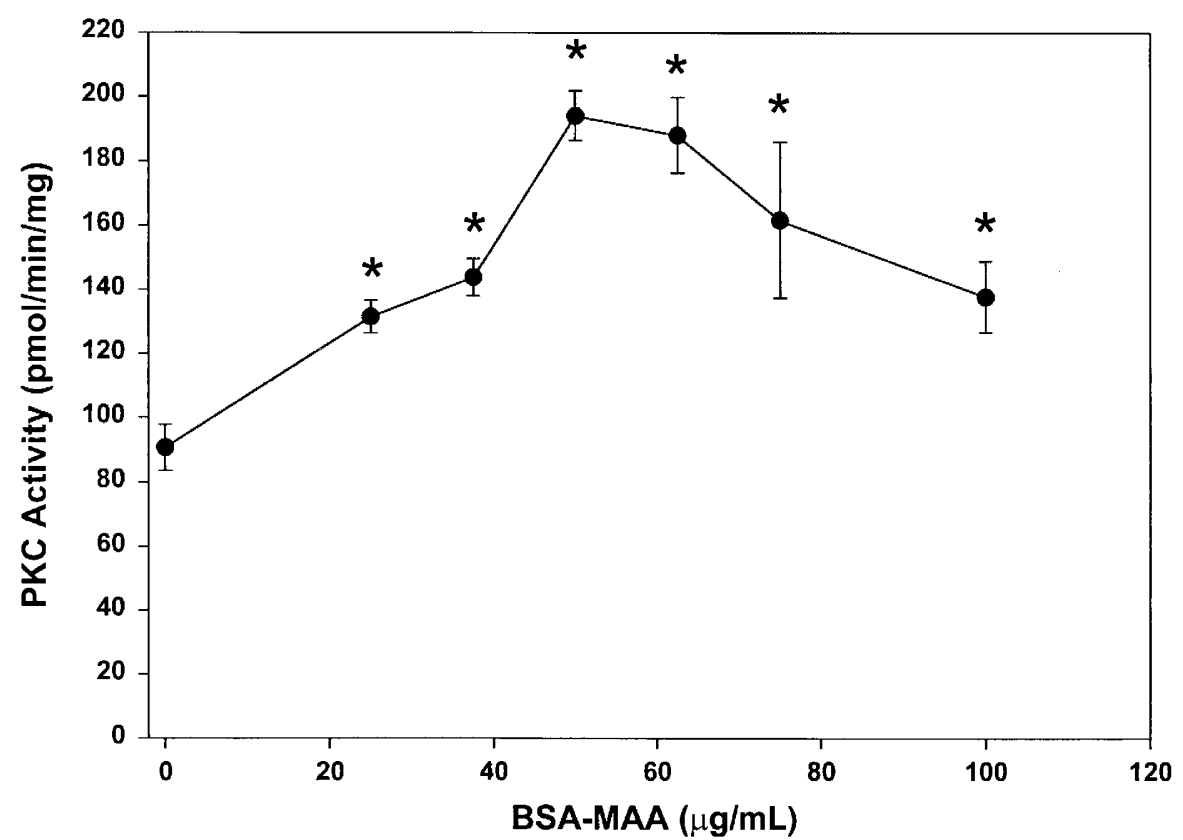

Fig. 2. Concentration-dependent effect of BSA-MAA on PKC activation. HSCs were exposed to different concentrations of BSA-MAA (0-100 $\mu \mathrm{g} / \mathrm{mL})$ for $2 \mathrm{hr}$, and PKC activity was determined. Results are presented as means \pm SEM of four determinations. HSCs were incubated with serum-free medium alone for $2 \mathrm{hr}$ as a control. An asterisk $(*)$ indicates that the value is significantly different $(P<0.05)$ from the control.

PKC- $\zeta$ (PKC- $\zeta$ specific inhibitor), or $1 \mu \mathrm{mol} / \mathrm{L}$ of calphostin $\mathrm{C}$ (isoform-indiscriminate general PKC inhibitor). Of all the inhibitors tested, only Gö 6976, the PKC- $\alpha$ specific inhibitor, and calphostin $\mathrm{C}$, an isoform-indiscriminate inhibitor, were able to inhibit the BSA-MAA-induced increase in PKC translocation, whereas rottlerin or myristylated-PKC- $\zeta$ had no effect (Fig. 3), indicating that the effects of MAA are mediated via the PKC- $\alpha$ isoform and not the PKC- $\delta$ or the $-\zeta$ isoform.

We next examined whether BSA-MAA-induced PKC activation could, in turn, modulate PA secretion by HSCs. HSCs were exposed to $50 \mu \mathrm{g} / \mathrm{mL}$ of BSA-MAA or the unmodified BSA for $24 \mathrm{hr}$, and the PA activity in the conditioned medium was quantified by a chromogenic substrate assay. We detected an $\sim 2$-fold increase in PA secretion by HSCs exposed to BSA-MAA as compared with the BSA-treated control (Fig. 4). It should be pointed out that when employing the chromogenic substrate assay, the only PA activity that we could demonstrate was with

Table 1

Effect of other aldehyde BSA-adducts on PKC activation

\begin{tabular}{llr}
\hline & \multicolumn{2}{l}{ PKC activity (pmol/(min mg) protein) } \\
\cline { 2 - 3 } & $2 \mathrm{hr}$ & \multicolumn{1}{c}{$24 \mathrm{hr}$} \\
\hline Unmodified BSA (control) & $129.3 \pm 30.4$ & $93.6 \pm 42.3$ \\
BSA-acetaldehyde & $142.3 \pm 20.8^{\mathrm{a}}$ & $147.6 \pm 5.2^{\mathrm{a}}$ \\
BSA-MDA & $103.6 \pm 25.6^{\mathrm{a}}$ & $144.6 \pm 14.5^{\mathrm{a}}$ \\
\hline
\end{tabular}

HSCs were exposed to $50 \mu \mathrm{g} / \mathrm{mL}$ of unmodified BSA, BSAacetaldehyde or BSA-MDA adducts for 2 and $24 \mathrm{hr}$, and the activity of $\mathrm{PKC}$ was determined as detailed in Section 2. Results are means $\pm \mathrm{SEM}$ $(N=4)$.

${ }^{\text {a }}$ Not significantly different from its corresponding control. using the conditioned medium. Leyland et al. [13], using acid glycine to dissociate protein-receptor interactions, had shown cell-surface associated PA in HSCs. However, we could not detect any cell receptor-associated PA activity when the cell surface was stripped with acid glycine.

The PA activity in the conditioned medium of the HSCs was also determined by casein-plasminogen-SDS-PAGE zymography. The underlying principle behind this technique is that following electrophoresis and renaturation, PA converts plasminogen, which is incorporated in the polyacrylamide gel, to plasmin which degrades the casein that is also incorporated into the gel. The degraded area appears unstained following staining with Coomassie blue. Not only is this technique widely used to semi-quantify PA activity, but it also gives an accurate determination of the molecular mass of the plasminogen activator. When conditioned media from HSCs were analyzed by the casein zymography technique, a prominent lytic band corresponding to a molecular mass of $\sim 33 \mathrm{kDa}$ was observed (Fig. 5). Densitometric analysis revealed a 2.2-fold increase in uPA secretion by HSCs treated with BSA-MAA as compared to those treated with BSA. No lytic bands were observed when the conditioned medium from cells exposed to either unmodified BSA or BSA-MAA-treated samples were analyzed by zymography in SDS-polyacrylamide gels containing only casein (data not shown). This indicated that plasmin was not being secreted by HSCs under basal or BSA-MAA-induced conditions. The conditioned medium obtained from these cells was also analyzed by a Western blotting technique using an antibody to uPA. Results showed a single sharp band representing the $33 \mathrm{kDa}$ uPA in medium from BSA-MAA or unmodified 


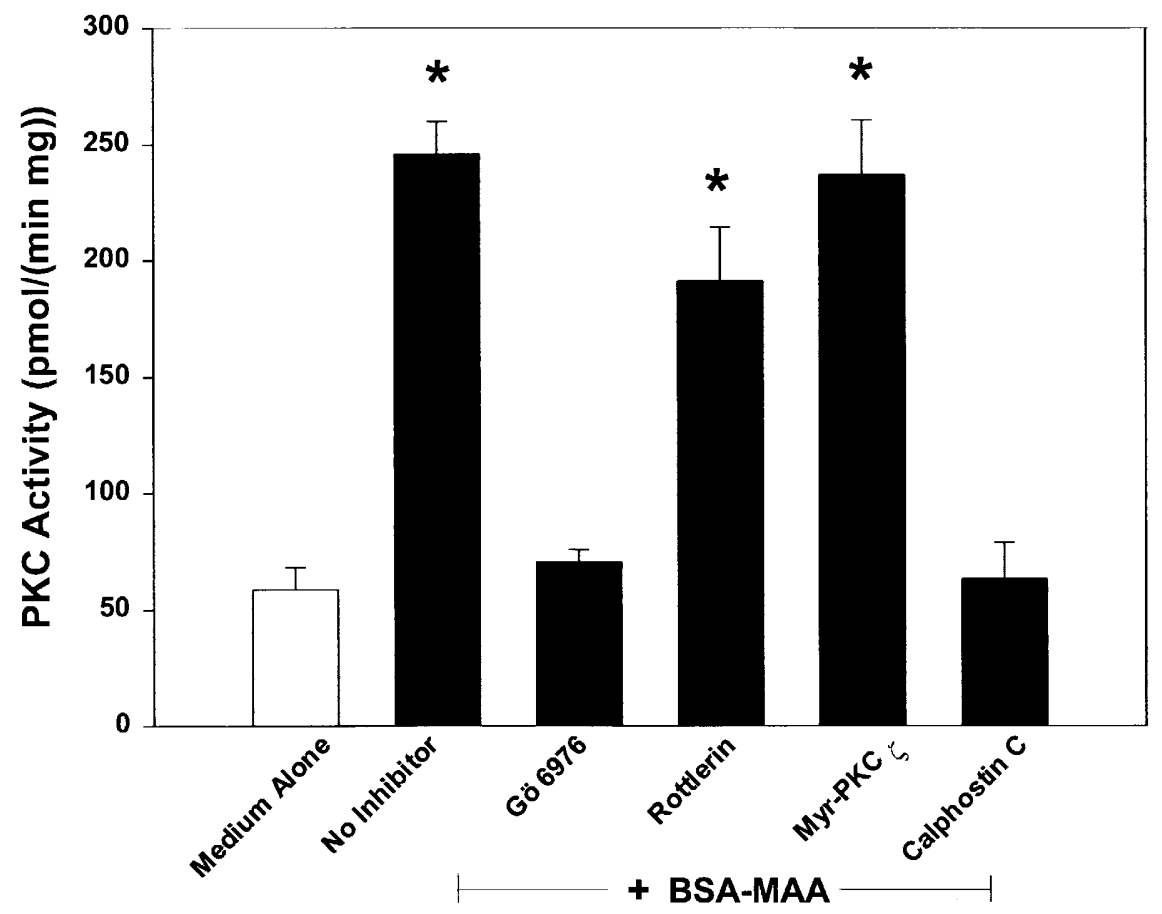

Fig. 3. Effect of PKC isoform-specific inhibitors on BSA-MAA-stimulated PKC activation. HSCs were exposed to isoform-specific inhibitors 1 hr before the addition of $50 \mu \mathrm{g} / \mathrm{mL}$ of BSA-MAA for $2 \mathrm{hr}$. The various inhibitors used were $100 \mathrm{nmol} / \mathrm{L}$ of Gö 6976 (PKC- $\alpha$ specific inhibitor), $2 \mu \mathrm{mol} / \mathrm{L}$ of rottlerin (PKC- $\delta$ specific inhibitor), $40 \mathrm{nmol} / \mathrm{L}$ of myristylated-PKC- $\zeta$ (PKC- $\zeta$ specific inhibitor), or $1 \mu \mathrm{mol} / \mathrm{L}$ of calphostin C (isoform-indiscriminate PKC inhibitor). HSCs were incubated with serum-free medium alone for $2 \mathrm{hr}$ to serve as a control. Results are presented as means \pm SEM of four determinations. An asterisk $(*)$ indicates that the value is significantly different $(P<0.05)$ from the control. No significant difference was observed when the samples treated with BSAMAA alone were compared with samples treated with myristylated-PKC- $\zeta+$ BSA-MAA or rottlerin + BSA-MAA.

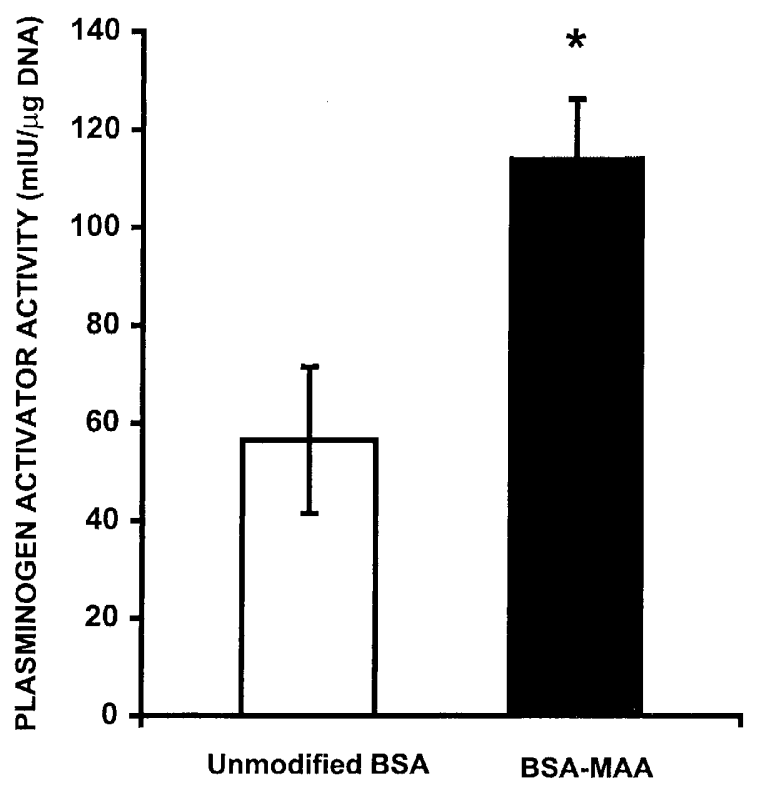

Fig. 4. Effect of BSA-MAA on PA activity in the conditioned medium. HSCs were exposed to $50 \mu \mathrm{g} / \mathrm{mL}$ of unmodified BSA or BSA-MAA for $24 \mathrm{hr}$, and the PA activity was determined in the conditioned medium using the chromogenic substrate assay as detailed in Section 2. Results are presented as means $\pm \mathrm{SEM}$ ( $N=4$ different cellular preparations). An asterisk $(*)$ indicates that the value is significantly different $(P<0.0008)$ from its corresponding control.
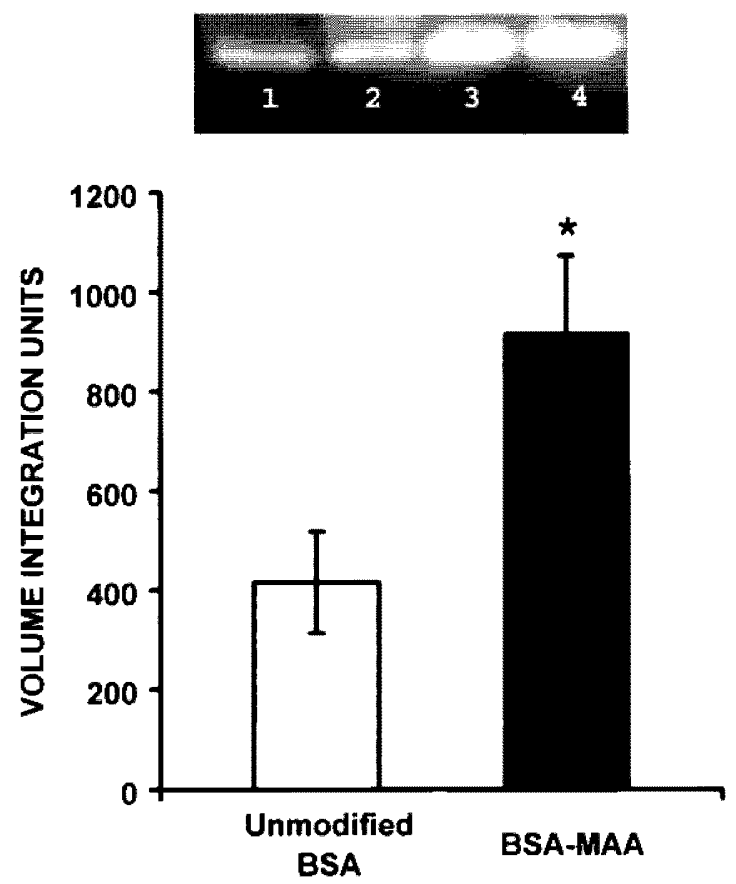

Fig. 5. SDS-PAGE zymograms showing the effect of BSA-MAA on the secretion of UPA. The conditioned medium of HSCs exposed to $50 \mu \mathrm{g} / \mathrm{mL}$ of unmodified BSA or BSA-MAA for $24 \mathrm{hr}$ was analyzed by SDS-PAGE zymography using plasminogen and casein as substrates as described in Section 2. Each column represents the mean $\pm \operatorname{SEM}(N=9$ different cellular preparations) of the volume integration units. An asterisk $(*)$ indicates $P<0.0006$. The zymogram shown above the columns is from one representative experiment. Lanes 1 and 2, BSA; lanes 3 and 4, BSAMAA. The lytic bands correspond to a molecular mass of $33 \mathrm{kDa}$. 


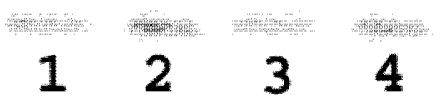

Fig. 6. Western blot analysis showing the effect of BSA-MAA on the secretion of uPA. Conditioned medium of HSCs exposed to $50 \mu \mathrm{g} / \mathrm{mL}$ of unmodified BSA or BSA-MAA for $24 \mathrm{hr}$ was separated on $10 \%$ PAGE, and proteins were transblotted onto nitrocellulose and stained with antibody to uPA as detailed in Section 2. Blots are from two separate experiments. The bands correspond to a molecular mass of $33 \mathrm{kDa}$. Lanes 1 and 3, BSA; lanes 2 and 4, BSA-MAA. The densitometric analyses, represented as mean volume integration units, are BSA, 51.9; BSA-MAA, 83.7.

BSA-treated HSCs (Fig. 6). This was similar to what was observed on the casein zymograms. Additionally, the Western blots corroborated our results obtained by both the chromogenic substrate assay and casein zymography, verifying that BSA-MAA induces increased secretion of $33 \mathrm{kDa}$ uPA. It is noteworthy that the $33 \mathrm{kDa}$ moiety corresponds to the active low molecular mass uPA, which has been shown to be devoid of binding sites for the uPA receptor on the cell surface. This could explain why we did not detect any cell-bound uPA in our chromogenic substrate assay.

To determine whether this BSA-MAA-induced increase in uPA was mediated via a PKC-dependent pathway, calphostin C, a PKC inhibitor, was added to the cells $1 \mathrm{hr}$ before the addition of unmodified BSA or BSA-
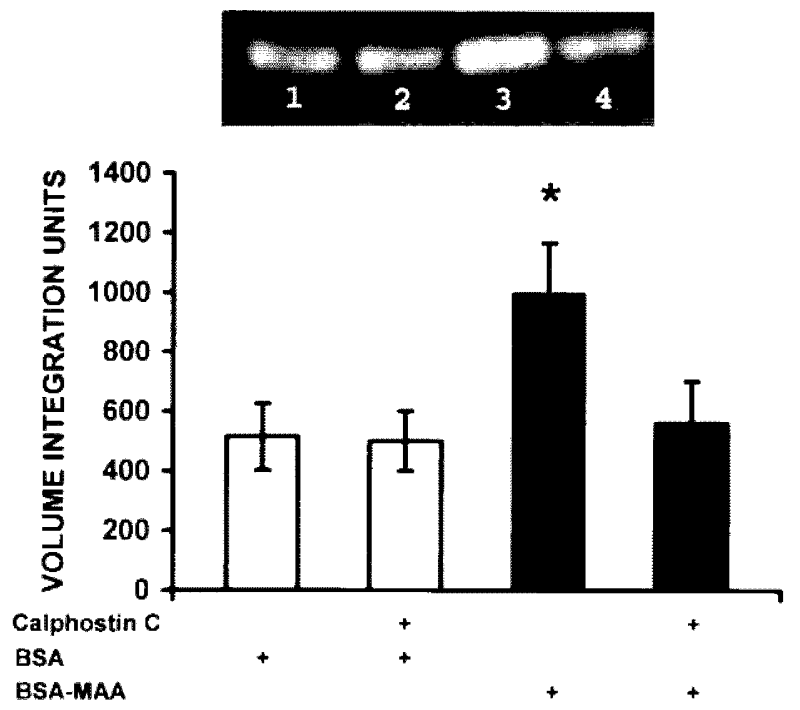

Fig. 7. Effect of calphostin C, a PKC inhibitor, on BSA-MAA-induced uPA activity in the conditioned medium analyzed by SDS-PAGE zymograms. HSCs were preincubated with or without $1 \mu \mathrm{mol} / \mathrm{L}$ of calphostin $\mathrm{C}$ for $1 \mathrm{hr}$ in serum-free medium. Then unmodified BSA or BSA-MAA $(50 \mu \mathrm{g} / \mathrm{mL}$ each) was added, and cells were incubated for another $24 \mathrm{hr}$. Conditioned medium was recovered and assayed for PA activity by SDS-PAGE zymography using plasminogen and casein as substrates as described in Section 2. Each column represents the mean of the volume integration units \pm SEM ( $N=5$ different cellular preparations). An asterisk $(*)$ indicates a value significantly different $(P<0.01)$ from the control. The zymogram shown above the columns is from one representative experiment. Lane 1, BSA; lane 2, calphostin C + BSA; lane 3, BSA-MAA; and lane 4, calphostin C + BSA-MAA.
MAA for $24 \mathrm{hr}$. We observed that calphostin $\mathrm{C}$ was able to abrogate significantly the BSA-MAA-induced uPA secretion by $90 \%$, but had no effect on the constitutive secretion of uPA (Fig. 7).

\section{Discussion}

In this study, we investigated the role of the PKC pathway in the transductional effects of MAA adducts on HSCs and their downstream effects. Our present study provides evidence that BSA-MAA utilizes the activation of a specific isoform of PKC, PKC- $\alpha$, as a possible pathway of signaling events in HSCs. Furthermore, our results indicate that PKC activation is necessary for BSAMAA-induced uPA secretion.

In experiments reported here, BSA-MAA induced a time-dependent activation of PKC in HSCs. Peak stimulation of PKC was observed $2 \mathrm{hr}$ after exposure to BSAMAA. In contrast to BSA-MAA, unmodified BSA did not stimulate PKC activity at any of the time points tested. The specificity of BSA-MAA on PKC activation in HSCs was also established by evaluating the effects of other aldehyde adducts. When examined at a concentration similar to that of BSA-MAA, which induced activation of PKC, no effect of BSA-acetaldehyde or BSA-MDA adduct was observed at either 2 or $24 \mathrm{hr}$ of treatment. In addition to the timedependent activation of PKC by BSA-MAA, we also observed a concentration-dependent stimulation of PKC activity in HSCs treated with $0-62.5 \mu \mathrm{g} / \mathrm{mL}$ of BSA-MAA for $2 \mathrm{hr}$. Although we observed a stimulation of PKC activity at 75 and $100 \mu \mathrm{g} / \mathrm{mL}$ of BSA-MAA as compared with the control, the stimulation in kinase activity was less than that observed at 50 and $62.5 \mu \mathrm{g} / \mathrm{mL}$ of BSA-MAA. We believe that we did not observe a concentration-dependent stimulation in PKC activity when HSCs were exposed to $>62.5 \mu \mathrm{g} / \mathrm{mL}$ of BSA-MAA for $2 \mathrm{hr}$ because of the possible down-regulation or auto-inhibition of PKC activity at $2 \mathrm{hr}$ when exposed to concentrations of BSA-MAA greater than $62.5 \mu \mathrm{g} / \mathrm{mL}$. Such concentration- and timedependent down-regulation of PKC has been documented in cells exposed to PMA, a known activator of PKC [32-34].

Since rat HSCs have been shown to express at least four different PKC isoforms, PKC $-\alpha,-\delta$, $-\varepsilon$, and $-\zeta[31]$, we also examined which PKC isoforms were activated by using isoform-specific inhibitors before exposing the cells to BSA-MAA. Of all the inhibitors tested, only Gö 6976 and calphostin $C$ were able to inhibit the increase in PKC translocation, indicating that the effects of BSA-MAA in HSCs are likely mediated via the PKC- $\alpha$ isoform.

We previously reported that BSA-MAA causes increased secretion of MCP-1 and MIP-2 by HSCs [22]. However, our observations that PKC inhibitors were unable to abrogate or mitigate the MAA-induced chemokine secretion (see footnote 1) implied that BSA-MAA does not utilize the PKC-mediated pathway to increase 
MCP-1 or MIP-2. We then explored other possible functional downstream effects of PKC activation in HSCs. The observations that PMA, a classical PKC activator, stimulates UPA expression in macrophages [26] and that rat HSCs produce uPA [13] led us to investigate whether BSA-MAA-induced PKC stimulation could, in turn, modulate PA secretion by HSCs. When HSCs were exposed to BSA-MAA, there was an increase of uPA secretion in the treated cells compared with the control cells, as quantified by the chromogenic substrate assay. These results on the BSA-MAA-induced increase in UPA were also corroborated by casein zymography. The advantage of using the casein zymography technique rather than the chromogenic substrate assay to semi-quantify the PA activity is that the molecular mass of the active moiety can be determined. Additionally, since HSCs have also been shown to secrete plasminogen activator inhibitor [35] and while the casein zymography technique will separate the inhibitor from the PA during electrophoresis, there is a probability of the inhibitor interfering in the chromogenic substrate assay, which could result in an underestimation of the PA activity. Because of the advantages listed above, we performed casein zymography and observed a significant increase in MAA-induced uPA secretion. To rule out the possibility that BSA-MAA is inducing the secretion of plasmin by the HSCs, the conditioned media were also separated on $10 \%$ SDS-polyacrylamide gels containing only $2 \mathrm{mg} / \mathrm{mL}$ of casein and no plasminogen. The lack of any lytic bands in these gels confirmed that the HSCs are induced to secrete $\mathrm{UPA}$, and not plasmin, after exposure to BSAMAA. Both Western blot analysis and casein zymography revealed that BSA-MAA increases secretion of $33 \mathrm{kDa}$ low molecular mass uPA. It was particularly intriguing that BSA-MAA induced an $\sim 2$-fold activation in PKC as well as an $\sim 2$-fold increase in secretion of uPA by HSCs. Furthermore, we observed that calphostin $\mathrm{C}$ was able to not only abrogate MAA-induced PKC activation, but also MAA-induced uPA secretion. The uPA activity measurements were obtained at $24 \mathrm{hr}$, well after the PKC activity has returned to unstimulated levels. This is a classical example of the signal transduction pathways where a cascade of events that are temporally and spatially linked takes place. Taken together, our results imply that the effect of BSA-MAA on promoting UPA secretion is mediated via a PKC-dependent pathway.

We have demonstrated for the first time that exposure of HSCs to MAA adducts can stimulate PKC activation, which leads to increased uPA secretion. We do not know at present whether the increased uPA secretion induced by BSA-MAA is a result of increased uPA gene expression or post-transcriptional modulation. The mechanism by which MAA adducts activate PKC is also presently unknown. However, we believe that the interaction of MAA adducts with surface receptors on HSCs results in the activation of PKC and generation of its downstream effects. In this regard, a family of receptors, classified as scavenger receptors [36], which are known to bind and endocytose a wide variety of aldehyde-adducted proteins, is a possible candidate for binding MAA adducts and initiating signaling events that lead to increased uPA secretion. Our hypothesis is supported by the report that binding of fucoidan or acetylated low-density lipoprotein to scavenger receptors on a macrophage cell line induces uPA expression via a PKC-mediated signaling pathway [37]. Current studies are in progress to investigate this mechanism.

In the studies reported here, we provide evidence that MAA adducts increase secretion of uPA by HSCs via a PKC-dependent pathway. The implications of our results are potentially important. The serine protease uPA cleaves its specific and intrinsic substrate, plasminogen, to generate plasmin. The broad-spectrum proteinase, plasmin, degrades fibrin and other components of the ECM [38], thereby playing an important role in physiological and pathological pathways involving cell migration and tissue remodeling. In addition, plasmin also regulates the activity of some members of the metalloproteinases that require activation, e.g. interstitial collagenase and stromelysin [39]. Through proteolysis, uPA also activates pre-interleukin 8 , hepatocyte growth factor, and vascular endothelial growth factor, and, via generation of plasmin, it activates transforming growth factor- $\beta$ [40-42]. Thus, the plasmingenerating system associated with HSCs plays a central role in the control of HSC biology by both regulating pericellular matrix degradation and activating fibrogenic growth factors. Beyond its role as a facilitator of extracellular proteolysis and an activator of growth factors, uPA has been reported to induce proliferation of HSCs [14]. Thus, BSA-MAA, by inducing increased uPA secretion by HSCs, could play a profound role in the perpetuation of alcoholic liver disease through matrix remodeling, generation of the most potent profibrogenic factor, transforming growth factor- $\beta$, and increased proliferation. Secretion of uPA has been shown to be increased by agents such as platelet-derived growth factor, basic-fibroblast growth factor, acetaldehyde, and retinoic acid, all of which have been shown to play an important role in the pathogenesis of alcoholic liver disease $[13,14,43]$. Thus, BSA-MAA can be added to the list of factors that may play an important role in the initiation and pathogenesis of alcoholic liver disease.

\section{Acknowledgments}

The authors thank Mary A. Forget, Thomas W. Halverson, and summer undergraduate students, Brian R. Cruz and Ryan C. Lynch, for their technical help. This research was supported, in part, by an MREP award (K.K.K.) from the Department of Veterans Affairs and, in part, by Grant AA-04961 (D.J.T.) from the National Institute on Alcohol Abuse and Alcoholism. 


\section{References}

[1] Friedman SL. Stellate cell activation in alcoholic fibrosis-an overview. Alcohol Clin Exp Res 1999;23:904-10.

[2] Gressner AM, Bachem MG. Molecular mechanisms of liver fibrogenesis-a homage to the role of activated fat-storing cells. Digestion 1995;56:335-46.

[3] Marra F. Hepatic stellate cells and the regulation of liver inflammation. J Hepatol 1999;31:1120-30.

[4] Milani S, Herbst H, Schuppan D, Hahn EG, Stein H. In situ hybridization for procollagen types I, III and IV mRNA in normal and fibrotic rat liver: evidence for predominant expression in nonparenchymal liver cells. Hepatology 1989;10:84-92.

[5] Maher JJ, McGuire RF. Extracellular matrix gene expression increases preferentially in rat lipocytes and sinusoidal endothelial cells during hepatic fibrosis in vivo. J Clin Invest 1990;86:1641-8.

[6] Matsuoka M, Tsukamoto H. Stimulation of hepatic lipocyte collagen production by Kupffer cell-derived transforming growth factor- $\beta$ : implication for a pathogenetic role in alcohol liver fibrogenesis. Hepatology 1990;11:599-605.

[7] Nakatsukasa H, Nagy P, Evarts RP, Hsia C-C, Marsden E, Thorgeirsson SS. Cellular distribution of transforming growth factor- $\beta 1$ and procollagen types I, III, and IV transcripts in carbon tetrachloride-induced rat liver fibrosis. J Clin Invest 1990;85:183343.

[8] Arthur MJ, Stanley A, Iredale JP, Rafferty JA, Hembry RM, Friedman SL. Secretion of $72 \mathrm{kDa}$ type IV collagenase/gelatinase by cultured human lipocytes: analysis of gene expression, protein synthesis and proteinase activity. Biochem J 1992;287:701-7.

[9] Milani S, Herbst H, Schuppan D, Grappone C, Pellegrini G, Pinzani M, Casini A, Calabro A, Ciancio G, Stefanini F, Burroughs AK, Surrenti C. Differential expression of matrix-metalloproteinase-1 and -2 genes in normal and fibrotic human liver. Am J Pathol 1994;144:528-37.

[10] Arthur MJ, Mann DA, Iredale JP. Tissue inhibitors of metalloproteinases, hepatic stellate cells and liver fibrosis. J Gastroenterol Hepatol 1998;13(Suppl):S33-8.

[11] Knittel T, Mehde M, Kobold D, Saile B, Dinter C, Ramadori G. Expression patterns of matrix metalloproteinases and their inhibitors in parenchymal and non-parenchymal cells of rat liver: regulation by TNF- $\alpha$ and TGF- $\beta 1$. J Hepatol 1999;30:48-60.

[12] Bissell DM, Wang SS, Jarnagin WR, Roll FJ. Cell-specific expression of transforming growth factor- $\beta$ in rat liver: evidence for autocrine regulation of hepatocyte proliferation. J Clin Invest 1995;96:447-55.

[13] Leyland H, Gentry J, Arthur MJ, Benyon RC. The plasminogenactivating system in hepatic stellate cells. Hepatology 1996;24: 1172-8.

[14] Fibbi G, Pucci M, Grappone C, Pellegrini G, Salzano R, Casini A, Milani S, Del Rosso M. Functions of the fibrinolytic system in human Ito cells and its control by basic fibroblast and platelet-derived growth factor. Hepatology 1999;29:868-78.

[15] Tuma DJ, Sorrell MF. Covalent binding of acetaldehyde to hepatic proteins: role in alcoholic liver injury. Prog Clin Biol Res 1985; 183:3-17.

[16] Tuma DJ, Sorrell MF. The role of acetaldehyde adducts in liver injury. In: Hall P, editor. Alcoholic liver disease: pathology and pathogenesis. London: Edward Arnold, 1995. p. 89-99.

[17] Niemela O, Parkkila S, Yla-Herttuala S, Halsted C, Witztum J, Lanca A, Israel Y. Covalent protein adducts in the liver as a result of ethanol metabolism and lipid peroxidation. Lab Invest 1994;70:537-46.

[18] Li C-J, Nanji AA, Siakotos AN, Lin RC. Acetaldehyde-modified and 4-hydroxynonenal-modified proteins in livers of rats with alcoholic liver disease. Hepatology 1997;26:650-7.

[19] Tuma DJ, Theile GM, Xu D, Klassen LW, Sorrel MF. Acetaldehyde and malondialdehyde react together to generate distinct protein adducts in the liver during long term ethanol administration. Hepatology 1996;23:872-80.

[20] Kearley ML, Patel A, Chien J, Tuma DJ. Observations of a new nonfluorescent malondialdehyde-acetaldehyde-protein adduct by ${ }^{13} \mathrm{C}$ NMR spectroscopy. Chem Res Toxicol 1999;12:100-5.

[21] Xu D, Theile GM, Beckenhauer JL, Klassen LW, Sorrell MF, Tuma DJ. Detection of circulating antibodies to malondialdehyde-acetaldehyde (MAA) adducts in ethanol-fed rats. Gastroenterology 1998;115:686-92.

[22] Kharbanda KK, Todero SL, Sorrell MF, Tuma DJ. MAA adducts increase chemokine production and the expression of cell adhesion molecule, ICAM-1, in hepatic stellate cells. Hepatology 1998; 28(Suppl):311A.

[23] Stubbs CD, Slater SJ. Ethanol and protein kinase C. Alcohol Clin Exp Res 1999;23:1552-60.

[24] Casini A, Galli G, Salzano R, Ceni E, Franceschelli F, Rotella C, Surrenti C. Acetaldehyde induces c-fos and c-jun proto-oncogenes in fat-storing cell cultures through protein kinase $\mathrm{C}$ activation. Alcohol 1994;29:303-14.

[25] Anania FA, Womack L, Potter JJ, Mezey E. Acetaldehyde enhances murine $\alpha 2(\mathrm{I})$ collagen promoter activity by $\mathrm{Ca}^{2+}$-independent protein kinase $\mathrm{C}$ activation in cultured rat hepatic stellate cells. Alcohol Clin Exp Res 1999;23:279-84.

[26] Falcone DJ, McCaffrey TA, Vergilio JA. Stimulation of macrophage urokinase expression by polyanions is protein kinase $\mathrm{C}$-dependent and requires protein and RNA synthesis. $J$ Biol Chem 1991;266:22726-32.

[27] Friedman SL, Roll FJ. Isolation and culture of hepatic lipocytes, Kupffer cells, and sinusoidal endothelial cells by density gradient centrifugation with Stractan. Anal Biochem 1987;161:207-18.

[28] Hannun YA, Loomis CR, Bell RM. Activation of protein kinase C by Triton X-100 mixed micelles containing diacylglycerol and phosphatidylserine. J Biol Chem 1985;260:10039-43.

[29] Labarca C, Paigen K. A simple, rapid, and sensitive DNA assay procedure. Anal Biochem 1980;102:344-52.

[30] Waghray A, Webber MM. Retinoic acid modulates extracellular urokinase-type plasminogen activator activity in DU-145 human prostatic carcinoma cells. Clin Cancer Res 1995;1:747-53.

[31] Britton RS, Bacon BR. Intracellular signaling pathways in stellate cell activation. Alcohol Clin Exp Res 1999;23:922-5.

[32] Ballester R, Rosen OM. Fate of immunoprecipitable protein kinase C in GH3 cells treated with phorbol 12-myristate 13-acetate. J Biol Chem 1985;260:15194-9.

[33] Hepler JR, Earp HS, Harden TK. Long-term phorbol ester treatment down-regulates protein kinase $\mathrm{C}$ and sensitizes the phosphoinositide signaling pathway to hormone and growth factor stimulation: evidence for a role of protein kinase $\mathrm{C}$ in agonist-induced desensitization. J Biol Chem 1988;263:7610-9.

[34] Young S, Parker PJ, Ullrich A, Stabel S. Down-regulation of protein kinase $\mathrm{C}$ is due to an increased rate of degradation. Biochem $\mathrm{J}$ 1987;244:775-9.

[35] Knittel T, Fellmer P, Ramadori G. Gene expression and regulation of plasminogen activator inhibitor type-1 in hepatic stellate cells of rat liver. Gastroenterology 1996;111:745-54.

[36] Gough PJ, Gordon S. The role of scavenger receptors in the innate immune system. Microbes Infect 2000;2:305-11.

[37] Hsu H, Hajjar D, Khan K, Falcone D. Ligand binding to macrophage scavenger receptor-A induces urokinase-type plasminogen activator expression by a protein kinase-dependent signaling pathway. Am Soc Biochem Mol Biol 1998;273:1240-6.

[38] Werb Z, Banda MJ, Jones PA. Degradation of connective tissue matrices by macrophages. Part I. Proteolysis of elastin, glycoproteins, and collagen by proteinases isolated from macrophages. J Exp Med 1980;152:1340-57.

[39] Murphy G, Atkinson S, Ward R, Gavrilovic J, Reynolds JJ. The role of plasminogen activators in the regulation of connective tissue metalloproteinases. Ann N Y Acad Sci 1992;667:1-12. 
[40] Naldini L, Tamagnone L, Vigna E, Sachs M, Hartmann G, Birchmeier W, Daikuhara Y, Tsubouchi H, Blasi F, Comoglio PM. Extracellular proteolytic cleavage by urokinase is required for activation of hepatocyte growth factor/scatter factor. EMBO J 1992;11:4825-33.

[41] Plouet J, Moro F, Bertagnolli S, Coldeboeuf N, Mazarguil H, Clamens S, Bayard F. Extracellular cleavage of the vascular endothelial growth factor 189-amino acid form by urokinase is required for its mitogenic effect. J Biol Chem 1997;272:13390-6.
[42] Rieder H, Armbrust T, Buschenfelde K-H, Ramadori G. Contribution of sinusoidal endothelial liver cells to liver fibrosis: expression of transforming growth factor- $\beta 1$ receptors and modulation of plasmingenerating enzymes by transforming growth factor- $\beta 1$. Hepatology 1993;18:937-44.

[43] Rodriguez-Fragoso L, Alvarez R, Reyes-Esparza JA, Garces ME. Acetaldehyde increases the activity and gene expression of urokinase type plasminogen activator in a hepatic stellate cell line. Toxicology 1999;137:1-11. 